\title{
Analysing the factors that influence the Pareto frontier of a bi-objective supply chain design problem
}

\author{
Antonio Palacio*, Belarmino Adenso-Díaz* ${ }^{* \Delta}$, Sebastián Lozano** \\ * Department of Industrial Engineering, University of Oviedo, Spain \\ ** Department of Industrial Management, University of Seville, Spain \\ $\triangle$ Corresponding author
}

\section{THIS PAPER WAS PUBLISHED IN 2018 IN INTERNATIONAL TRANSACTION IN OPERATIONAL RESEARCH doi: https://doi.org/10.1111/itor.12493}

\begin{abstract}
In this paper a bi-objective multi-product model for the design of a production/distribution supply chain logistic network with four echelons is considered. The proposed optimization model minimizes the total cost of the network (including the fixed cost to open facilities and the transportation costs between them) and the total $\mathrm{CO}_{2}$ emissions. Five factors (network size, product complexity, cost variability, $\mathrm{CO}_{2}$ emissions generation and over-capacity) are considered for the experimental framework. The problem is solved using the $\varepsilon$-constraint method and the resulting Pareto frontiers are characterized using five new metrics specifically developed for analysing how those factors affect the resulting optimal configurations. The results show that over-capacity and product complexity are the two most influential factors regarding the characteristics of the Pareto frontier, and that their effects are in the same direction: more complexity and capacity mean a wider set of optima alternatives, some close to the ideal point, and in general with a smaller number of links used.
\end{abstract}


Keywords: logistics network design; bicriteria optimization; Pareto frontier; cost minimization; emissions minimization; product complexity 


\section{Introduction}

A supply chain logistic network can be described as a graph where the nodes represent suppliers, producers/manufacturers, distribution centres, warehouses, and customers; and the set of arcs represent the transportation links between these facilities. Although there are other nodes that can be considered when designing a supply chain logistic network (e.g. recycling centres, assemblers, recovery plants) those four echelons are those traditionally taken into account when analysing supply networks (Sabri and Beamon, 2000).

During the last decades the study of logistic networks has grown notably with many works studying different kinds of problems related to supply chains. Note that most of these studies only consider a single objective function, usually cost (Mangiaracina et al., 2015). However, this may be insufficient today due to the increase in the complexity of the management of supply chains in recent decades, with an increase in competition, lead times reduction, operational risk, environmental constraints, etc. Hence, considering multiple objectives simultaneously when designing logistics structures is a field that represents a more realistic view of the current situation.

This research effort in designing better multiobjective logistics networks is expanding this field and involves different approaches. They can be divided into different groups according to their research objectives, the corresponding decisions in the design process, and the corresponding solution methodologies.

Regarding the first dimension, there are many different objectives that have been studied simultaneously in multiobjective optimization problems; revenue, sustainability, lead times, service level, financial criteria, and production-related objectives are the most popular. Profit-related objectives are included in almost every piece of research because minimization of costs (or maximization of profit) is generally considered as the 
first key objective. The rest of the objectives can be found in combination with the cost minimization objective, depending on the particular interest of the company or researcher, with sustainability, lead time and service level (i.e. percentage demand fulfilled) as the most popular. Figure 1 gives a summary of the number of references dealing with multiobjective approaches to logistic network design.

The second dimension, namely the decisions to be made in a logistic network design process, is another important aspect when dealing with a multiobjective problem. The most common decisions in a logistic network are the facilities' locations and the transportation flows. There are some cases where this problem is extended to include capacity decisions both for the facilities and the transportation links, or routing (Lopes et al., 2013). Other decisions in multiobjective logistic networks that are frequently studied are the number of products manufactured, the inventory levels of the facilities and the uncertainty level (Mangiaracina et al., 2015).

Finally, regarding the solution methodologies for multiobjective logistic network design problems, many different alternatives exist, including exact and metaheuristic methods, depending on the type of mathematical model and its complexity. A well known taxonomy for multiobjective optimization techniques can be found in Marler and Arora (2004), which presented a review dividing them into methods with no articulation of preferences, methods with a priori articulation of preferences, methods with $a$ posteriori articulation of preferences (which include multiobjective evolutionary algorithms) and interactive multiobjective optimization methods.

Regardless of whether a single objective or a multiobjective approach is used to design a supply chain network, it is clear that there are many factors, some of them uncontrollable (e.g. infrastructure, Customs clearance, etc., see Önsel Ekici et al., 2016) 
that affect the optimal design. In their review of the topic, Mangiaracina et al. (2015) identified 42 factors affecting the performance of supply chain networks, which they grouped into five clusters; the most recurrent were related to demand as well as to service requirement. They note that issues, such as the number of plants and specialisation level of factories, have been considered in many researches (e.g. Ambrosino and Scutella, 2005). Also, supplier related variables, such as number of suppliers and items, are relevant from the point of view of the modeller (Creazza et al., 2010). Many researchers have studied how some relevant factors, such as network size (e.g. Özceylan, 2016), or collection complexity in the case of reverse supply chains (e.g. Zikopoulos and Tagaras, 2015), affect the design of the supply chain, but these studies generally consider a single criterion, namely cost minimization. To the best of our knowledge there has not been any previous attempt to study how different factors affect the performance of a supply network gauged using multiple objective functions.

In this paper, we consider a bi-objective multi-product model for a production/distribution supply chain logistic network with four echelons (suppliers, plants, warehouses and customers). The aim of the model is to minimize the total cost of the network (including the fixed cost of suppliers, plants and warehouses, and the cost of the components' flows between consecutive echelons) as well as to minimize the total $\mathrm{CO}_{2}$ emissions (including the total $\mathrm{CO}_{2}$ emissions of the facilities and of transport). Regarding the solution methodology, the $\varepsilon$-constraint method (Ehrgott and Ruzika, 2008) is used to find the set of Pareto-optimal solutions for the problem. The research objective is to use this modelto better understand how the quality of the potential solutions (in terms of cost and $\mathrm{CO}_{2}$ emissions targets) change, depending on certain characteristics of the network (size, complexity, capacity, cost variability, etc.). Note that this means analysing the characteristics of different Pareto-optimal solutions sets, each one corresponding to a different instance, trying to come to some conclusions 
about the nature of the solutions, depending on some factors characterizing the instances. As far as we are aware, nothing similar has been done before. There are many papers (see for example Berezkin and Lotov, 2014) that compare different approximations of the Pareto frontier (PF) (obtained using different methods) but for a specific instance. However, in this paper we compute, using the $\varepsilon$-constraint method, the PF corresponding to different instances, proposing different metrics to analyse and compare the characteristics of these solutions sets.

The structure of the paper is as follows. In section 2 a brief literature review of multiobjective production/distribution networks is presented. In section 3 the biobjective model and the proposed solution methodology are presented. Section 4 reports the results of the experimental design carried out. Finally, in section 5, the summary and conclusions of this study are presented.

\section{Literature review}

Although supply production/distribution networks have been studied for years it has not been until recently that researchers began to consider multiobjective supply chains' designs. The different objectives considered in the literature can be classified into four main groups: economic, sustainability, service level and time-related. Since historically supply chain network design has been strongly linked to the profit/cost criterion, most of the multiobjective papers have at least one of their objectives related to economic aspects such as cost minimization, profit maximization or network present value (NPV) maximization.

Several authors have considered, along with the economic objective, the minimization of the environmental impact or sustainability-related objectives. Thus, Luo et al. (2001) considered the maximization of productivity and the minimization of cycle time in addition to costs and environmental impact. Meanwhile, Dotoli et al. 
(2006) considered, as additional objectives, the minimization of both energy consumption and total lead time. For measuring the environmental impact Life Cycle Assessment (LCA) is the most common methodology. Thus, for example, Amin and Zhang (2013) modified their three-echelon closed-loop supply chain network cost minimization model, introducing environmental issues and defining new parameters for the use of environmentally friendly materials and clean technology. You et al. (2012) also used LCA in the design of sustainable cellulosic biofuel supply chains. Other researchers have used well-known Life Cycle Impact Assessment (LCIA) methodologies, such as Eco-Indicator 99 (e.g. Hugo and Pistikopoulos, 2005; Pishvaee and Razmi, 2012) or Ecoinvent (e.g. Ruiz-Femenia et al., 2013). But perhaps the most common multiobjective approach is to minimize cost and $\mathrm{CO}_{2}$ emissions (e.g. Nurjanni et al., 2017), sometimes also minimizing other pollutants (e.g. Kadziński et al., 2017).

Another type of objective that is often studied, combined with cost minimization, is related to the time dimension, such as minimizing tardiness, lead time or transport time. Thus, for example, Farahani and Elahipanah (2008) designed a threeechelon supply chain to determine the transportation flows between facilities by considering two objective functions: the minimization of transportation, holding and purchasing costs, and minimization of the earliness and tardiness of deliveries. Similarly, cost and tardiness minimization can be found in Du and Evans (2008) and Pishvaee and Torabi (2010). These two objectives plus a third one (maximization of the coverage of customer zones) can be found in Li et al. (2012); they study the location of the collection points and repairing centres as well the transportation flows among facilities in a reverse logistics network. Minimizing costs and delays are also considered in Javanshir et al. (2012); these determine the production plan, flows and number of distribution centres that must be opened to satisfy customers' demand. Other researchers (e.g. Cardona-Valdés et al., 2011; Olivares-Benitez et al., 2012) have 
studied the Capacitated Fixed Cost Facility Location Problem with Transportation Choices determining the location of distribution centres and the flows between the facilities, in order to minimize the costs and transportation time of the product from the plant to the customer.

Another objective, usually related to time, is maximization of the customer service level (a.k.a. fill or service rate). That is because improvements in transportation times, tardiness or delivery times, lead to improvements in customer service levels. Pishvaee et al. (2010) studied an integrated forward/reverse network determining the location, number and capacity of facilities and the transportation flows between them. They considered as objectives the minimization of the total cost of the system and the maximization of the responsiveness as the ratio of the quantity of products shipped from distribution centres to customers and the total amount of products demanded by customers. Latha Shankar et al. (2013) measured the customer service level by the product fill rate and the cycle service level (i.e. fraction of replenishment cycles that result in all the customer demands being met). Razmi et al. (2013) also considered the service level by maximizing the coverage percentage of customer demand delivered within the preferred delivery lead time, by considering multiple scenarios with a given probability of occurrence.

Other criteria that can be found in combination with cost minimization include total cost variance and financial risk (Azaron et al., 2008) and delivery reliability (Pokharel, 2008). It is also common, in the case of closed-loop supply chains, to minimize costs and risk due to uncertainty in demand, recovery and disposal rates (e.g. Dai and Dai, 2016).

There are also studies that maximize profit instead of minimizing cost. Thus, for example, Chen et al. (2003) consider as objectives the maximization of profit and the maximization of the average inventory level. Chen and Lee (2004) added to those 
objectives the maximization of the average customer service level and the maximization of the network robustness. Franca et al. (2010) considered as objectives the maximization of profit and the minimization of the suppliers' defects. Pinto-Varela et al. (2011) combined the maximization of profit with minimization of the environmental impact. Amin and Zhang (2012) maximize profit, minimize defect rates and maximize the importance of external suppliers. Ramezani et al. (2013) maximize total profit and customer service level and minimize total defective raw material.

\section{Methodology}

Let us consider a standard supply chain logistic network (e.g. Sabri and Beamon, 2000; Pokharel, 2008) with four echelons (suppliers, plants, warehouses and customers; see Figure 2) in a multiproduct environment where the customer demand for each product is known. The aim of the problem is to satisfy the demand of each customer from the different plants using the appropriate warehouses and suppliers' configuration.

We will consider a bi-objective optimization approach, taking into account on the one hand the minimization of the total cost, and on the other hand the minimization of the total $\mathrm{CO}_{2}$ emissions. Two different costs are considered: fixed cost (i.e., the operating cost of the facilities) associated with each node of the graph (excluding customers), and the costs of the transportation links between nodes (i.e. the transportation costs between facilities, and between facilities and customers). Regarding the emissions, each node (again excluding customers) and transportation link has an associated index, which represents the amount of emissions generated expressed as a percentage of the flow in that node or link. 
The operation of the supply chain represented in our model is as follows: suppliers provide components and raw materials to plants for manufacturing the products. The number of components and the composition of products (i.e. the quantity of each component needed to be manufactured) are known as well as the typs of components that can be provided by each supplier. With the components/raw materials received from suppliers, plants manufacture the products and send them to warehouses. Finally, products are distributed from warehouses to each customer satisfying their demand. We consider a capacitated model, i.e. every facility and transportation link has an associated limit on the amount of each product or component processed or transported.

The notation used in our model is as follows (see Figure 2):

$\mathrm{K}$ : Set of products to manufacture.

B: Set of components/raw materials needed for the manufacture.

$\mathrm{B}(\mathrm{k})$ : Set of components/raw materials needed to manufacture product $\mathrm{k}$.

$\mathrm{S}(\mathrm{b})$ : Set of suppliers that provide component/raw material b.

$\mathrm{P}(\mathrm{k})$ : Set of plants that manufacture product $\mathrm{k}$.

$D_{c}^{k}$ : Demand of customer c for product $\mathrm{k}$.

$g_{b}^{k}$ : Quantity of component/raw material $\mathrm{b}$ needed to manufacture a unit of product $\mathrm{k}$.

$U_{s}^{b}$ : Capacity of suppliers as regards component/raw material b.

$U_{p}^{k}, U_{w}^{k}$ : Capacity of plant $\mathrm{p}$ and warehouse $\mathrm{w}$, respectively, as regards product $\mathrm{k}$.

$U_{s p}^{b}, U_{p w}^{k}, U_{w c}^{k}$ : Transport capacities between two consecutive echelons. 
$c_{s p}^{b}, c_{p w}^{k}, c_{w c}^{k}:$ Transport unit cost between two consecutive echelons.

$F_{s}, F_{p}, F_{w}:$ Fixed operating cost for suppliers, plants and warehouses.

$r_{s p}^{b}, r_{p w}^{k}, r_{w c}^{k}:$ Emission rate between two consecutive echelons.

$r_{s}^{b}, r_{p}^{k}, r_{w}^{k}:$ Emission rate of suppliers, plants and warehouses.

$z_{s}, z_{p}, z_{w}$ : Binary variables for the opening of suppliers, plants and warehouses.

$x_{s p}^{b}, x_{p w}^{k}, x_{w c}^{k}$ : Quantity of material sent between two consecutive echelons.

With all this information, the proposed model used for deciding the optimal configuration is [1]-[12]:

$$
\begin{aligned}
\operatorname{Min} & \sum_{k} \sum_{w} \sum_{c} c_{w c}^{k} \cdot x_{w c}^{k}+\sum_{k} \sum_{p \in P(k)} \sum_{w} c_{p w}^{k} \cdot x_{p w}^{k}+ \\
& +\sum_{k} \sum_{p \in P(k)} \sum_{b \in B(k)} \sum_{s \in S(b)} c_{s p}^{b} \cdot x_{s p}^{b}+\sum_{w} F_{w} \cdot z_{w}+\sum_{p} F_{p} \cdot z_{p}+\sum_{s} F_{s} \cdot z_{s} \\
\operatorname{Min} & \sum_{k} \sum_{w} \sum_{c}\left(r_{w c}^{k}+r_{w}^{k}\right) x_{w c}^{k}+\sum_{k} \sum_{p \in P(k)} \sum_{w}\left(r_{p w}^{k}+r_{p}^{w}\right) x_{p w}^{k}+ \\
& +\sum_{k} \sum_{p \in P(k)} \sum_{b \in B(k)} \sum_{s \in S(b)}\left(r_{s p}^{b}+r_{s}^{b}\right) x_{s p}^{b}
\end{aligned}
$$

s.t.

$\sum_{w} x_{w c}^{k}=D_{c}^{k} \quad \forall c \forall k$

$\sum_{p \in P(k)} x_{p w}^{k}=\sum_{c} x_{w c}^{k} \quad \forall w \forall k$

$$
\sum_{s \in S(b)} x_{s p}^{b}=\sum_{k} g_{b}^{k} \sum_{w} x_{p w}^{k} \quad \forall p \forall b
$$


$x_{w c}^{k} \leq U_{w c}^{k} \quad \forall w \forall c \forall k$

$x_{p w}^{k} \leq U_{p w}^{k} \quad \forall w \forall k \forall p \in P(k)$

$x_{s p}^{b} \leq U_{s p}^{b} \quad \forall p \in P(k) \forall b \in B(k) \forall s \in S(b)$

$\sum_{c} x_{w c}^{k} \leq U_{w}^{k} \cdot z_{w} \quad \forall w \forall k$

$\sum_{w} x_{p w}^{k} \leq U_{p}^{k} \cdot z_{p} \quad \forall k \forall p \in P(k)$

$\sum_{p} v_{s p}^{b} \leq U_{s}^{b} \cdot z_{s} \quad \forall k \forall b \in B(k) \forall s \in S(b)$

$x_{w c}^{k}, x_{p w}^{k}, v_{s p}^{b} \geq 0 \quad \forall c \forall w \forall k \forall p \in P(k) \forall b \in B(k) \forall s \in S(b)$

$z_{w}, z_{p}, z_{s} \in\{0,1\} \quad \forall w \forall p \forall s$

The first objective function represents the total cost, including the fixed cost of open suppliers, plants and warehouses, the cost of component/raw material flows between suppliers and plants, the cost of product flows between plants and warehouses, and the cost of product flows from warehouses to customers. The second objective function minimizes the total $\mathrm{CO}_{2}$ emissions, including the total $\mathrm{CO}_{2}$ emissions at the facilities and the total $\mathrm{CO}_{2}$ emissions due to transport.

Regarding the constraints, [3] ensures that the demand of all customers must be satisfied; [4] ensures that the quantity of product $k$ transported from the different plants to warehouse $w$ is exactly the same as the total amount of product $k$ transported from warehouse $w$ to customers; [5] ensures that the quantity of component/raw material $b$ transported from suppliers to plant $p$ is equal (using the corresponding gozinto factors) to the quantity of products generated in plant $p$ and hence transported from plant $p$ to 
warehouses; [6]-[7] ensure that the transportation flows of product $k$ from plants to warehouses and from warehouses to customers do not exceed the corresponding capacities on those links; [8] ensures that the transportation flows of component/raw material $b$ from suppliers to plants do not exceed the corresponding capacities on those links. Analogously, [9]-[11] ensure that the capacities of facilities are not exceeded. Finally, constraint sets [12] and [13] ensure that all flows are non-negative and that the facilities opening decision variables are binary, respectively.

\section{Experimental results}

In order to solve the above model, the $\varepsilon$-constraint method is used. This methodology, introduced by Haimes et al. (1971), consists of the minimization of the main objective function considering all the other objectives as additional constraints on the model, using the appropriate bounds (in our case, bounding the emissions while minimizing cost). By imposing successively decreasing bounds $\varepsilon_{i}$ on the secondary objective function a sample of Pareto optimal solutions can be found. As seen in Figure 3, when minimizing just the cost we obtain the point $\mathrm{C}$ of the $\mathrm{PF}$ with a total emissions of Em; if we minimize cost imposing an emission upper bound of $\varepsilon_{1}=\mathrm{Em}-\Delta$, a new point in the PF is obtained, the same is done with $\varepsilon_{2}=\mathrm{Em}-2 * \Delta=\varepsilon_{1}-\Delta$ and so on until reaching the minimum value of emissions $\mathrm{E}^{*}$, which corresponds to a cost $\mathrm{Cm}$. The value of $\Delta$, i.e. the separation between two successive upper bounds, depends on the number of Pareto optimal points that we want to compute. In our case, $\Delta=\left(E m-E^{*}\right) / 21$.

As regards the $\varepsilon$-constraint method in general, an incorrect selection of bounds could lead to a formulation without a feasible solution. There are also multiple studies on the methods for the selection of the bounds reflecting preferences (e.g. Goicoechea et al., 1976; Cohon, 1978; Carmichael 1980). In our case, the emissions bounds go from 
Em to $\mathrm{E}^{*}$, so finding a solution is guaranteed. In general, the solutions obtained using the $\varepsilon$-constraint method are weak Pareto-optimal and every weak Pareto-optimal point can be obtained if the feasible region is convex and all the objective functions are explicitly quasi-convex (Ruíz-Canales and Rufian-Lizana, 1995). If the solution is unique, then it is Pareto optimal. Anyway, even though any Pareto optimal solution can be found with some effort, there may be difficulties in specifying the corresponding upper bounds (Miettinen, 1999).

FIGURE 3

\subsection{Comparing Pareto frontiers}

For the analysis of the solutions of the proposed approach, we will generate 22 points in each of the PFs for each instance solved: two corresponding to the extreme points in the $\mathrm{PF}$ ( $\mathrm{C}$ and $\mathrm{D}$ in Figure 3) plus 20 intermediate points corresponding to bounding emission by $\varepsilon_{i}=\mathrm{Em}-i \Delta \forall i=1 . .20$, with $\Delta=\left(\mathrm{Em}-\mathrm{E}^{*}\right) / 21$. Although the number of non-dominated points computed in most papers dealing with PF estimation is much larger (which allows a much more precise determination of the $\mathrm{PF}$ ), in our case the objective of the research is not to solve a specific instance. Instead, in our case, the objective of the research is to compare the behaviour of the PFs for problems with different characteristics, and for doing so, what we need is to identify the same number of points on the PF for each problem. In this case, we found that 22 points give enough information for that comparison.

Having obtained the PF corresponding to the different instances, it is not straightforward how to compare those sets of solutions. For this purpose, we have developed five different measures for the evaluation of the PF that can be used to identify the main characteristics of each PF. The first three metrics are defined analysing the decision space (the optimum values of the decision variables such as open 
facilities or links used), and the last two metrics are defined on the objective space (i.e., on the values of the two objective functions associated to each solution in the PF):

1. Average difference in open facilities (ADOF). We note that each point of the PF corresponds to a specific design of the logistic network (i.e. a configuration), including open facilities and flows (Figure 3). Thus, apart from the associated network flows $\left\{x_{s p}^{b}, x_{p w}^{k}, x_{w c}^{k}\right\}$, that PF point has an associated vector $\mathrm{Z}=\{0,1\}^{\mathrm{n}}$ indicating which facilities (i.e. nodes) are open. Looking at that information, we can compare the two solutions corresponding to two PF points A and B by using the Hamming distance $\mathrm{d}(A, B)=\sum_{i}\left|Z_{i}^{A}-Z_{i}^{B}\right|$. The ADOF is defined for each instance by calculating this distance between each pair of $\mathrm{PF}$ points (i.e. $22 \times 21 / 2=231$ distances) and taking the average of all of them. Small values of $\mathrm{ADOF}$ mean that most points in the PF open the same facilities (independently of the product flows among them).

2. Number of different "open facilities" solutions (NDOFS) in the PF. A variant of the previous idea is to count the times that the exact same facilities are open in the solutions of the PF. A small value means that there are only a few optimal alternatives regarding the facilities opened (although the flows among them could imply different costs and emissions).

3. Percentage of links used (PLU) in the solutions. Considering now the flows in the solutions, an interesting characteristic of a specific solution is the total number of links used (number of links with non-zero flows $x_{s p}^{b}, x_{p w}^{k}, x_{w c}^{k}$ ), as a percentage of the total number of potential links of the network, and calculate the average for the different points of the PF. High values of PLU mean that the network density and complexity increases as more connections (i.e. transportation links) are used. 
4. Percentage of area of the rectangle covered (PARC). Another characteristic of interest is how far the PF is from the ideal point I (see Figure 3). To measure this issue, we use the ratio PARC between the area of the points dominated by the PF (shaded in Figure 3), and the area of the rectangle C-I'-D-I. Therefore, a value close to 1 means that there exist solutions in the PF close to both minimum cost and minimum emissions, and therefore to the Ideal Point I, so that solutions with a good compromise between both objective functions could be found. This measure is analogous to the biobjective case of the hypervolume of Zitzler et al. (2003).

5. Distance between extreme solutions $\mathbf{C}$ and $\mathbf{D}$ (DES). The last measure we consider is the length of the segment $\mathrm{CD}$, i.e. the Euclidean distance between the best cost solution and the best emissions solution. High values of DES mean that the Pareto optimal solutions can be very different (some with low cost and high emissions, and others with low emissions and high cost).

\subsection{Experimental framework}

The above five measures are used to analyse the shape of the PFs obtained in an experimental framework involving five different factors (each with two levels) that were considered relevant for this problem:

F1. Network size. This factor takes into account the number of nodes on each echelon of the network. At the low level we consider $\mathrm{N}=5$ nodes for suppliers, plants and warehouses and $\mathrm{M}=250$ nodes for customers; the high level considers $\mathrm{N}=10$ nodes for suppliers, plants and warehouses and $\mathrm{M}=500$ nodes for customers. 
F2. Product Complexity. This factor takes into account the complexity in the manufacturing of the products (the number of products manufactured and the number of facilities that can supply each component or manufacture each product). We consider two complexity levels for F2 with instances randomly generated using the values shown in Table 1, depending on the values of F1.

F3. Cost Variability. The influence of the difference of the cost coefficients inside the echelons is considered here. For each echelon, the fixed costs of the facilities and unit transportation costs of the links are randomly generated from uniform distributions according to the two levels considered (see Table 2).

F4. Emissions generation. This factor determines the intensity of the emissions generation in the facilities and links. The values are randomly generated from uniform distributions according to the two levels considered: $\mathrm{U}(0.008,0.12)$ for the low level; $\mathrm{U}(0.05,0.15)$ for the high level, in all the cases.

F5. Over-capacity. The last factor considered is the over-capacity of the facilities and links with respect to the demand to be satisfied. In this case, the two levels are low and high over-capacity. For the low over-capacity level we consider that the ratio between the demand and the overall sum of capacities is around 0.5 , while for the case of high over-capacity we consider that the ratio between the demand and the overall sum of capacities is around 0.25 (i.e. the demand is not so critical, when considering the available capacity). 
Therefore, the experimental framework has a total of $2^{5}=32$ factor level combinations (treatments). Five instances for each factor level have been generated and each one has been solved using the $\varepsilon$-constraint method. Thus, in total we have 160 instances and a 22-point PF for each instance. R statistical software (https://www.r-project.org/) was used for all the statistical analysis.

\subsection{Results and discussion}

Depending on the factors used for defining the instances, the shape of the corresponding PFs are expected to be different (see Figure 4) and can thus be analysed using the five metrics proposed. Starting with the ADOF metric, the boxplot charts (Figure 5) suggest that factors F2 (product complexity) and F5 (over-capacity) results are especially significant regarding the average difference in open facilities of the resulting PFs. The corresponding ANOVA (Table 3) confirms that both factors are the most significant affecting this metric. Therefore, a smaller number of similar configurations regarding the opening of facilities are obtained when the product complexity is low or when the capacity is becoming a problem. Also, ANOVA shows that factor F1 (network size) has a somewhat significant influence as well.

For the second metric (NDOFS) the boxplot chart (Figure 6) indicates again that factors F1, F2 and F5 seem to significantly affect the number of different optimal solutions that can be found for each instance -something that again ANOVA confirms. This means that when the size of the problem is smaller, the product structure is simpler or the over-capacity is low (no over-capacity), in general there are just a few optimal options as regards the different facilities to open. 
Regarding the PLU, it can be clearly seen in Figure 7 that factor F5 (overcapacity) and also F2 (product complexity) have a big influence in this metric. Since in this case normality is not granted, we used a nonparametric Mann-Whitney U Test to confirm $(p \approx 0.0)$ the influence of both factors. Therefore, a smaller number of links are used when the product structure is more complex or when the capacity is enough for the requested demand (not requiring alternatives for transportation).

As regards the PARC metric, according to the boxplots shown in Figure 8, the factors with more influence in this measure seem to be F1, F3 and F5, which is confirmed by the corresponding ANOVA. In general, points closer to the ideal point can be found for smaller networks (F1 low level) than for larger ones. When cost variability in each echelon is low, points closer to the ideal point can also be computed. Finally, the same result is obtained when there is large over-capacity.

FIGURE 8

Finally, as regards the DES, the boxplots in Figure 9 suggest that factors F2 and F5 are those with the largest influence. As this DES response variable does not fulfil the conditions required for an ANOVA study, the nonparametric Mann-Whitney U Test is used again to confirm the assumption that F2 and F5 are significant $(\mathrm{p} \approx 0.0)$. Therefore, when the product structure is less complex or when the over-capacity is low (tight capacity available), the difference between the points corresponding to the minimum cost and the minimum emission solutions is smaller. 
The influence of each of the five factors on each metric is summarized in Table 4. The most influential factor is the amount of over-capacity (F5): when the overcapacity is high (i.e., there are enough resources to cover the demand), more optimal solutions with different open facilities appear in the PF, a smaller percentage of links are used, the distance between the minimum cost and minimum emissions points is larger and the PF in general contains points close to the ideal solution. Similar effects can be observed for the next influential factor, product complexity (F2).

Network size (F1) also has some influence on the number of different open facilities in the solutions (higher when the network size is large) as well as on the possibility of finding points close to the ideal (less likely when the network size is large). Cost variability (F3) also has an influence as regards the possibility of finding points close to the ideal (it is more likely to find points close to the ideal point when costs of the different facilities in an echelon are more similar). Finally, the emissions generation factor $(\mathrm{F} 4)$ does not seem to have much influence on the type of solutions that form the PF.

TABLE 4

Given the relationship between the two factors capturing complexity (namely, F1 complexity of the network, F2 complexity of the product design), it may be expected some type of interaction between both factors. As Figure 10 shows, there is indeed an interaction although only for the metric PARCS. A high value of this measure means that the PF contains points that are close to the minimum values in both cost and emissions dimension. Hence, the interaction detected means that when the product complexity is low, the PARC measure is similar whether the network is complex or not but when the product is complex, PARC is much higher in the case of a simpler network than when the network is more complex. 
The approach followed above is based on the usual practice of considering cost minimization as the main goal (as most real companies do) and imposing emissions bounds. However, when identifying a small number of points in the PF, the solutions found can be different depending on the objective function chosen as primary. As it can be seen in Figure 11, when the main objective function is cost minimization the computed Pareto optimal points tend to concentrate on the left side of the Pareto front, where the slope of the curve increases and larger emissions increases occur per unit cost reduction. The opposite occurs when it is $\mathrm{CO}_{2}$ emissions that is the main objective function. In that case, the computed Pareto optimal points tend to concentrate on the right side of the Pareto front, where the marginal cost increases per unit emissions reductions are larger. Hence, some of the characteristics of the computed PF can be different depending on the objective function chosen as primary. Thus, no significant difference should be expected for the metrics corresponding to the objective space (of course no difference at all for DES, and with a sampling of $15 \%$, i.e., 24 instances, a difference of only a $0.04 \%$ was found for PARC). Regarding the metrics on the decision space, again a small difference was found in our sampling for the PLU metric (only a $1.5 \%)$. Slightly bigger differences are found when looking at the two metrics dealing with the number of facilities open (3.81 vs. 3.64 for ADOF, and 14.7 vs. 11 for NDOFS), since depending on the extreme of the PF, the facilities used for delivering the products are different.

FIGURE 11

\section{Conclusions}

This paper defines a bi-objective multi-product model for a production/distribution logistic network with four echelons considering not only the 
cost of the operating facilities and the costs of transport between suppliers, warehouses and customers, but also the emissions generation in each facility and in the transport operations.

Five factors are considered in order to study different scenarios, our goal being to study the characteristics of the PF solutions obtained, depending on the network type. To do so, five new measures were defined to characterize the different PFs obtained: the average difference in the facilities open, the number of different open facilities solutions, the closeness to the ideal point, the percentage of arcs used in the solutions, and the distance between the extreme points in the FP.

The results obtained were analysed with $\mathrm{R}$ software in order to study the influence of the different factors on each measure. It was found that the level of overcapacity and the product complexity have the largest influence in the Pareto optimal solutions of the supply chain design problem, having a significant impact on all five measures defined. Large over-capacity implies more alternative solutions with different facilities open, more extreme optimal costs/emissions solutions, fewer arcs used and less difficulty to obtain PF points close to the ideal. High product complexity has almost the same effects (except in the difficulty to compute PF points close to the ideal). A smaller influence has the network size, with larger networks leading to more alternative Pareto-optimal solutions and solutions less close to the ideal. Finally, higher cost variance seems to affect the possibility of finding solutions close to the ideal.

We can therefore conclude that the consideration of more than one objective function allows trade-offs between them and that the shape and extension of the corresponding PF depend on a number of factors, especially on the over-capacity level and the product complexity. Thus, the higher both factors are, the smaller is the number of arcs used and the higher the diversity of Pareto optimal solutions that can be 
computed. From a managerial point of view, we observe that designing networks with a large capacity in their elements, represents not only advantages in terms of risk minimization, but also making available many more alternative good solutions to choose from, in order to define good configurations, considering both cost and emissions minimization.

With respect to further research, an important issue to consider is to analyse the case when not only emissions are generated but there can also be different levels of spoilage depending on the facilities and the transportation links used.

Acknowledgements. This research was carried out with the financial support of the Spanish Ministry of Science and the European Regional Development Fund (ERDF), grant DPI2017-85343-P.

\section{References}

Ambrosino, D., Scutella, M.G., 2005. "Distribution network design: new problems and related models". European Journal of Operational Research 165, 3, 610-624.

Amin, S.H., Zhang, G., 2012. "An integrated model for closed-loop supply chain configuration and supplier selection: Multi-objective approach". Expert Systems with Applications 39, 6782-6791.

Amin, S.H., Zhang, G., 2013. "A multi-objective facility location model for closed-loop supply chain network under uncertain demand and return”. Applied Mathematical Modelling 37, 4165-4176.

Azaron, A., Brown, K.N., Tarim, S.A., Modarres, M., 2008. "A multi-objective stochastic programming approach for supply chain design considering risk". International Journal of Production Economics 116, 129-138. 
Berezkin, V.E., Lotov, A.V., 2014. "Comparison of two Pareto Frontier Approximations". Computational Mathematics and Mathematical Physics 54, 9, 14021410.

Cardona-Valdés, Y., Álvarez, A., Ozdemir, D., 2011. “A bi-objective supply chain design problem with uncertainty". Transportation Research Part C 19, 821-832.

Carmichael, D.G., 1980. "Computation of Pareto optima in structural design". Int. J. Numerical Methods in Engineering 15, 925-952.

Chen, C.L., Lee, W.C., 2004. "Multi-objective optimization of multi-echelon supply chain networks with uncertain product demands and prices". Computers and Chemical Engineering 28, 1131-1144.

Chen, C.L., Wang, B.W., Lee, W.C., 2003. "Multiobjective optimization for a multienterprise supply chain network". Industrial \& Engineering Chemistry Research 42, 1879-1889.

Cohon, J.L., 1978. "Multiobjective Programming and Planning". New York: Academic Press.

Creazza, A., Dallari, F., Meacini, M. 2010. "Evaluating logistics network configurations for a global supply chain”. Supply Chain Management-An International Journal 15, 2, 154-164.

Dai, Z., Dai, H.M., 2016. "Bi-objective closed-loop supply chain network design with risks in a fuzzy environment". Journal of Industrial and Production Engineering 33, 3, 169-180.

Dotoli, M., Fanti, M.P., Meloni, C., Zhou, M., 2006. "Design and Optimization of Integrated E-supply Chain for Agile and Environmentally Conscious Manufacturing". IEEE Transactions on Systems, Man, and Cybernetics - Part A: Systems and Humans $36,1,62-75$.

Du, F., Evans, G.W., 2008. "A bi-objective reverse logistics network analysis for postsale service". Computers \& Operations Research 35, 2617-2634.

Ehrgott, M., Ruzika, S., 2008. "Improved $\varepsilon$-constraint method for multiobjective programming". Journal of Optimization Theory and Applications 138, 3, 375-396. 
Farahani, R.Z., Elahipanah, M., 2008. "A genetic algorithm to optimize the total cost and service level for just-in-time distribution in a supply chain". International Journal of Production Economics 111, 229-243.

Franca, R.B., Jones, E.C., Richards, C.N., Carlson, J.P., 2010. "Multiobjective stochastic supply chain modeling to evaluate tradeoffs between profit and quality". International Journal of Production Economics 127, 292-299.

Goicoechea, A., Duckstein, L., Fogel, M.M., 1976. "Multiobjective programming in watershed management: A case study of the Charleston watershed". Water Resources Research 12, 1085-1092.

Haimes, Y.Y., Lasdon, L.S., Wismer, D.A., 1971. "On a bicriterion formulation of the problems of integrated system identification and system optimization". IEEE Transactions System, Man \& Cybernetics SMC-1,3, 296-297.

Hugo, A., Pistikopoulos, E.N., 2005. "Environmentally conscious long-range planning and design of supply chain networks". Journal of Cleaner Production 13, 1471-1491.

Javanshir, H., Ebrahimnejad, S., Nouri, S., 2012. "Bi-objective supply chain problem using MOPSO and NSGA-II". International Journal of Industrial Engineering Computations 3, 681-694.

Kadziński, M., Tervonen, T., Tomczyk, M.K. and Dekker, R., 2017. "Evaluation of multi-objective optimization approaches for solving green supply chain design problems. Omega 68, 168-184.

Latha Shankar, B., Basavarajappa, S., Chen, J.C.H., Rajeshwar, S., Kadadevaramath, S., 2013. "Location and allocation decisions for multi-echelon supply chain network: A multi-objective evolutionary approach". Expert Systems with Applications 40, 551-562.

Li, S., Wang, N., He, Z., Che, A., Ma, Y., 2012. 'Design of a multiobjective reverse logistics network considering the cost and service level". Mathematical Problems in Engineering, art. no. 928620.

Lopes, R.B., Ferreira, C., Santos, B.S., Barreto, S., 2013. "A taxonomical analysis, current methods and objectives on location-routing problems". International Transactions in Operational Research 20, 6, 795-822 
Luo, Y., Zhou, M., Caudill, R. J., 2001. “An Integrated E-Supply Chain Model for Agile and Environmentally Conscious Manufacturing". IEEE/ASME Transactions on Mechatronics 6, 4, 377-386.

Marler, R.T., Arora, J.S., 2004. "Survey of multi-objective optimization methods for engineering”. Structural Multidisciplinary Optimization 26, 369-395

Mangiaracina, R., Song, G., Perego, A., 2015. "Distribution network design: A literature review and a research agenda". International Journal of Physical Distribution \& Logistics Management 45, 5,506-531.

Miettinen, K., 1999. "Nonlinear Multiobjective Optimization". Boston: Kluwer Academic Publishers.

Olivares-Benitez, E., González-Velarde, J.L., Ríos-Mercado, R.Z., 2012. "A supply chain design problem with facility location and bi-objective transportation choices". Top 20, 3, 729-753.

Önsel Ekici, S., Kabak, O., Ülengin, F., 2016. "Linking to compete: Logistics and global competitiveness interaction". Transport Policy 48, 117-128.

Özceylan, E., 2016. "Simultaneous optimization of closed- and open-loop supply chain networks with common components". Journal of Manufacturing Systems 41, 143-156.

Pinto-Varela, T., Barbosa-Póvoa, A.P.F.D., Novais, A.Q., 2011. "Bi-objective optimization approach to the design and planning of supply chains: Economic versus environmental performances". Computers and Chemical Engineering 35, 1454-2468.

Pishvaee, M.S., Farahani, R.Z., Dullaert, W., 2010. "A memetic algorithm for biobjective integrated forward/reverse logistics network design”. Computers \& Operations Research 37, 1100-1112.

Pishvaee, M.S., Razmi, J., 2012. "Environmental supply chain network design using multi-objective fuzzy mathematical programming”. Applied Mathematical Modelling 36, 3433-3446.

Pishvaee, M.S., Torabi, S.A., 2010. "A possibilistic programming approach for closedloop supply chain network design under uncertainty". Fuzzy Sets and Systems 161, 2668-2683. 
Pokharel, S., 2008. "A two objective model for decision making in a supply chain". International Journal of Production Economics 111, 378-388.

Nurjanni, K.P., Carvalho, M.S., Costa, L., 2017. "Green supply chain design: A mathematical modelling approach based on a multi-objective optimization model". International Journal of Production Economics 183, 421-432.

Ramezani, M., Bashiri, M., Tavakkoli-Moghaddam, R., 2013. "A new multi-objective stochastic model for a forward/reverse logistic network design with responsiveness and quality level". Applied Mathematical Modelling 37, 328-344.

Razmi, J., Zahedi-Anaraki, A.H., Zakerinia, M.S., 2013. "A biobjective stochastic optimization model for reliable warehouse network redesign". Mathematical and Computer Modelling 58, 1804-1813.

Ruiz-Canales, P., Rufian-Lizana, A., 1995. "A characterization of weakly efficient points", MathematicalProgramming 68, 205-212.

Ruiz-Femenia, R., Guillén-Gonsálbez, G., Jimenez, L., Caballero, J.A., 2013. "Multiobjective optimization of environmentally conscious chemical supply chains under demand uncertainty". Chemical Engineering Science 95, 1-11.

Sabri, E.H., Beamon, B.M. 2000. "A multi-objective approach to simultaneous strategic and operational planning in supply chain design”. Omega 28 (5), 581-598.

You, F., Tao, L., Graziano, D.J., Snyder, S.W., 2012. "Optimal design of sustainable cellulosic biofuel supply chains: Multiobjective optimization coupled with life cycle assessment and input-output analysis". American Institute of Chemical Engineering 58, $1157-1180$

Zikopoulos, C., Tagaras, G., 2015. "Reverse supply chains: Effects of collection network and returns classification on profitability". European Journal of Operational Research 246, 435-449.

Zitzler, E., Thiele, L., Laumanns, M., Fonseca, C.M., da Fonseca, V.G., 2003. "Performance assessment of multiobjective optimizers: an analysis and review". IEEE Transactions on Evolutionary Computation 7, 2, 117-132. 
FINANCE

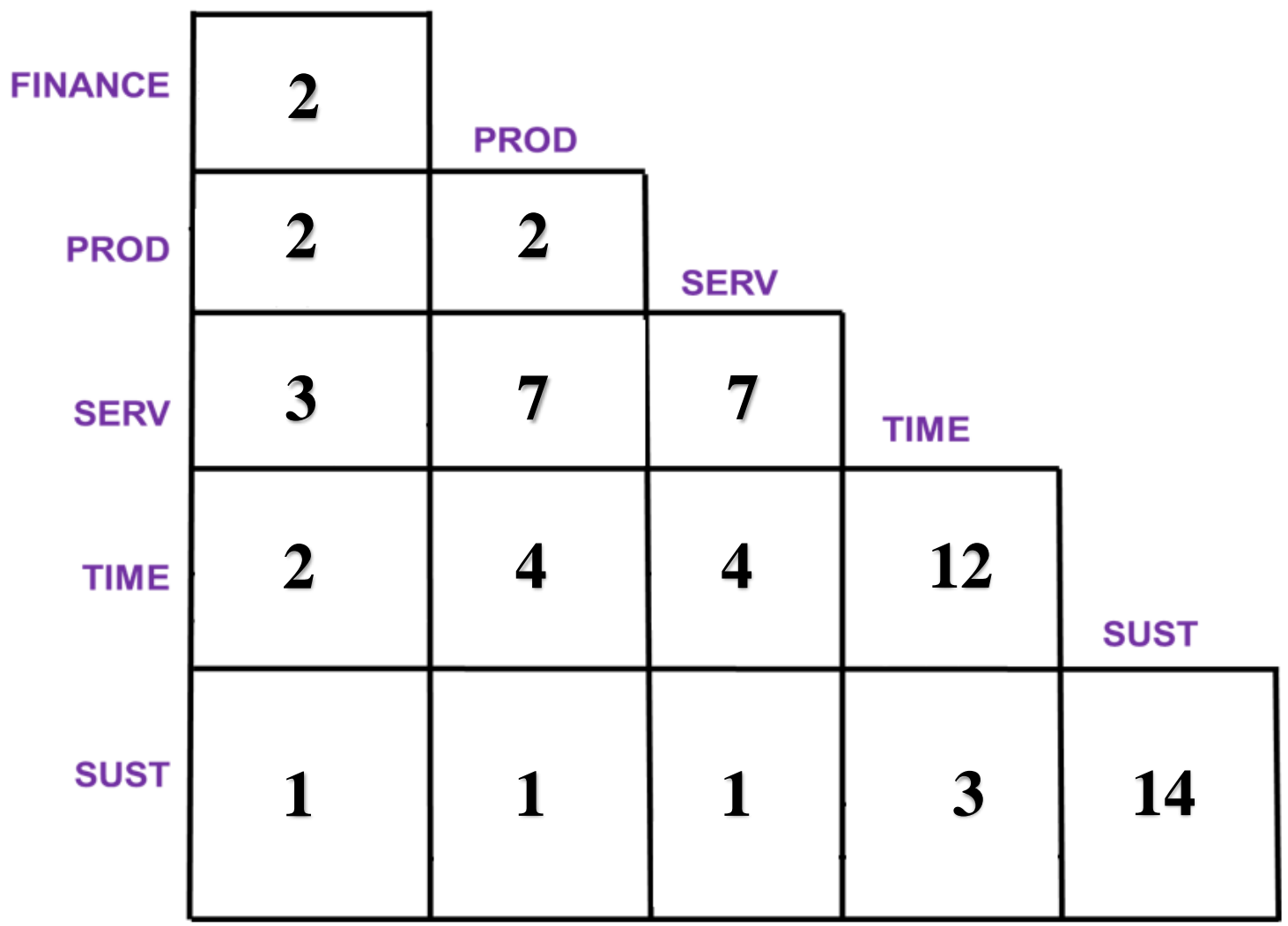

Figure 1. Number of references (period 2000-2015) dealing with multiobjective supply chain network design (all of them include in addition cost/profit optimization; for instance, dealing with sustainability, time and cost/profit, 3 papers were found; dealing with time and cost/profit, 12 papers were found). 


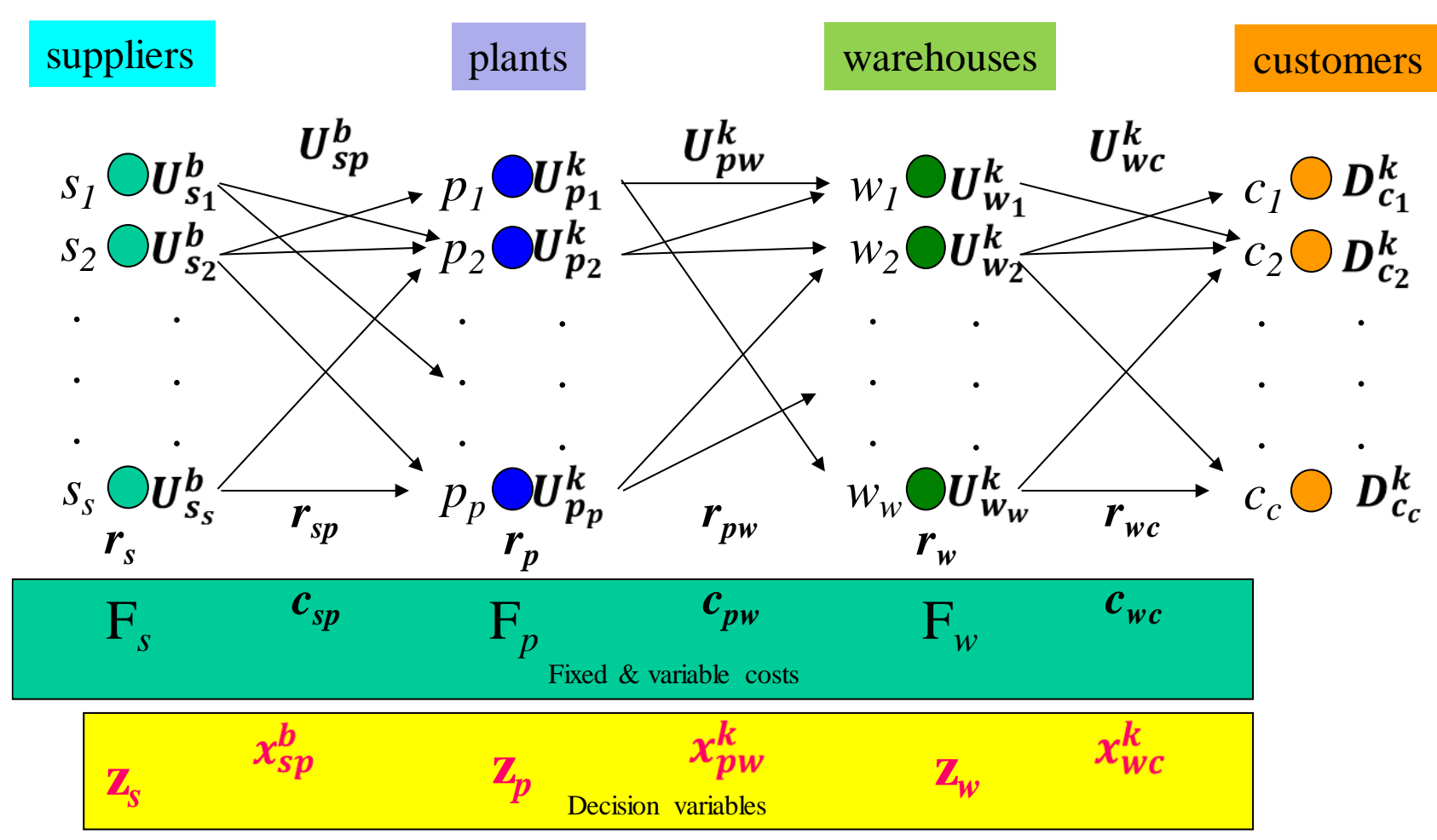

Figure 2. Four-echelon supply chain, and involved parameters and decision variables 


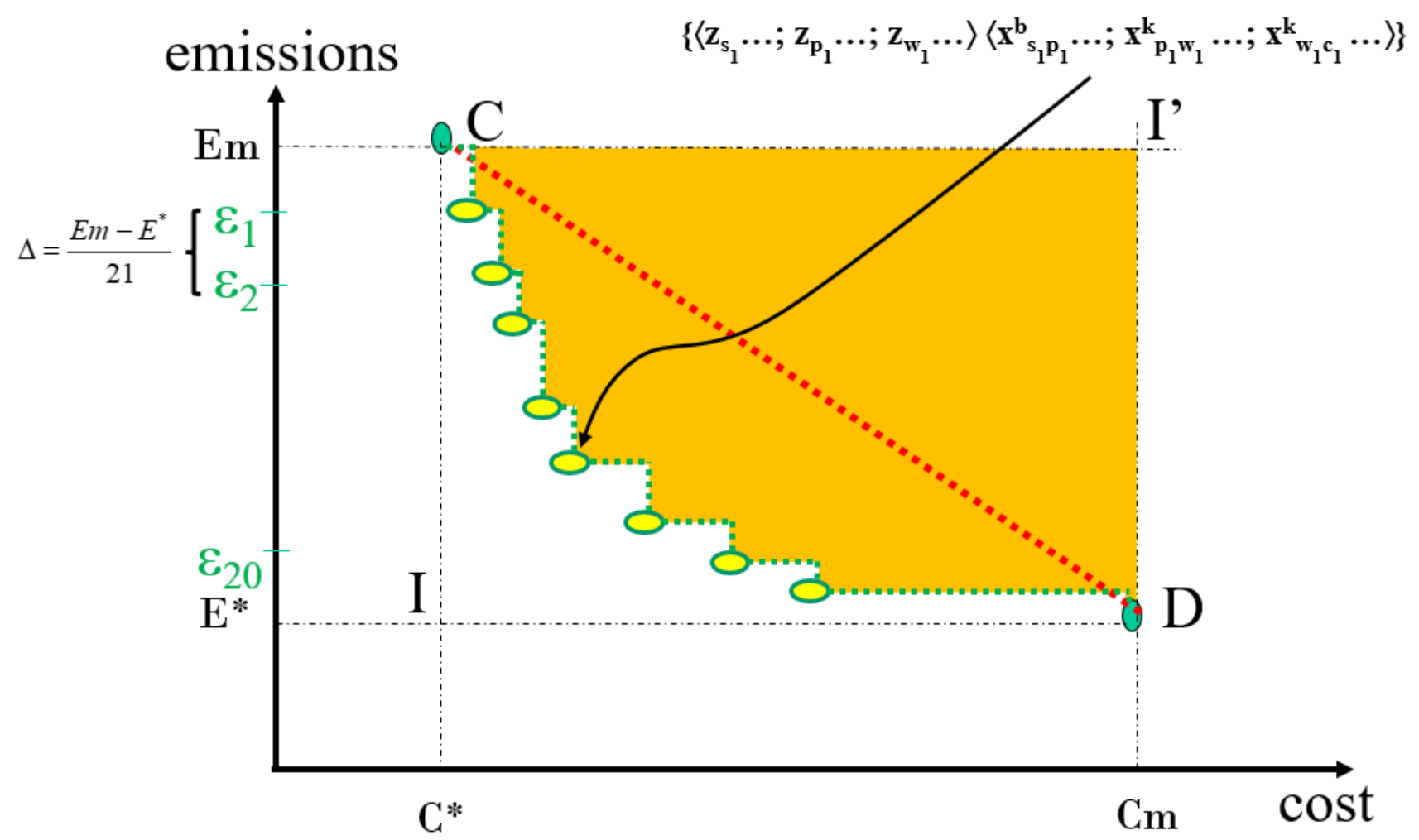

Figure 3. Pareto Frontier for cost and emissions. Each point includes information about the facilities to open, and the flows among them. 

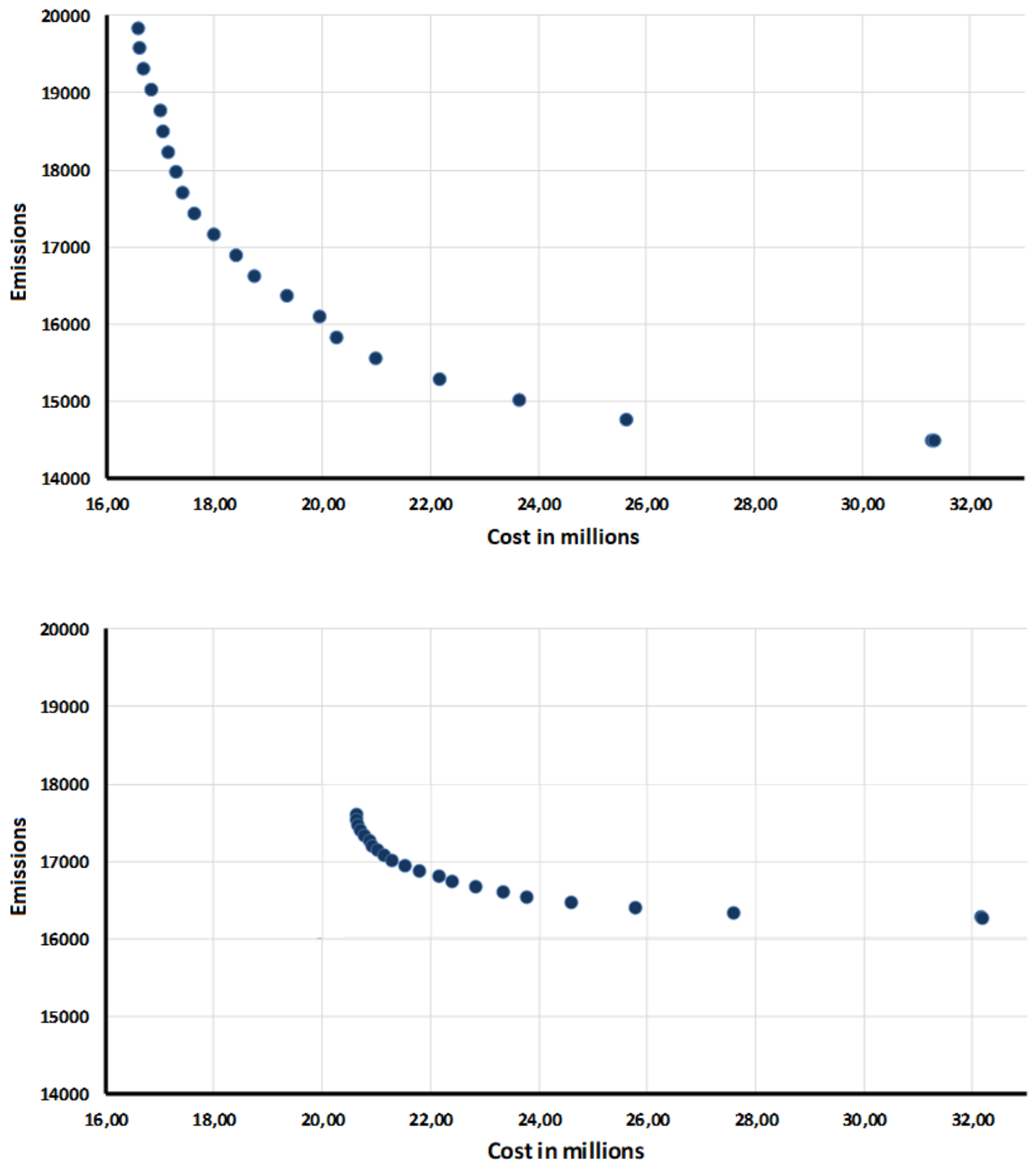

Figure 4. Points in the PF for two different instances (corresponding to treatment $\langle\mathrm{H}-\mathrm{H}-$ $\mathrm{H}-\mathrm{H}-\mathrm{H}\rangle$ above, and $\langle\mathrm{H}-\mathrm{H}-\mathrm{L}-\mathrm{L}-\mathrm{H}\rangle$ below), showing different shapes 

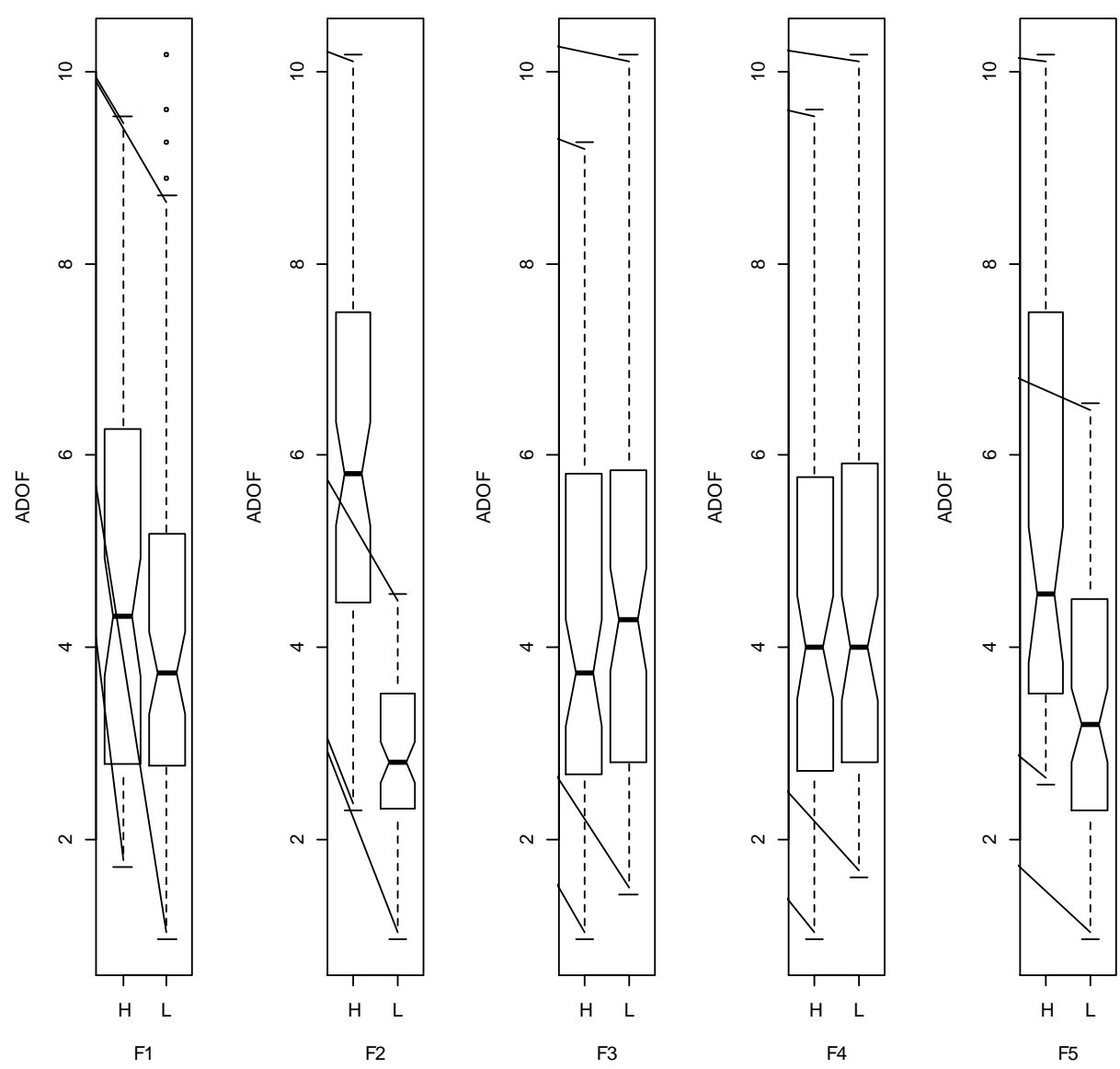

Figure 5. ADOF boxplotfor each factor 

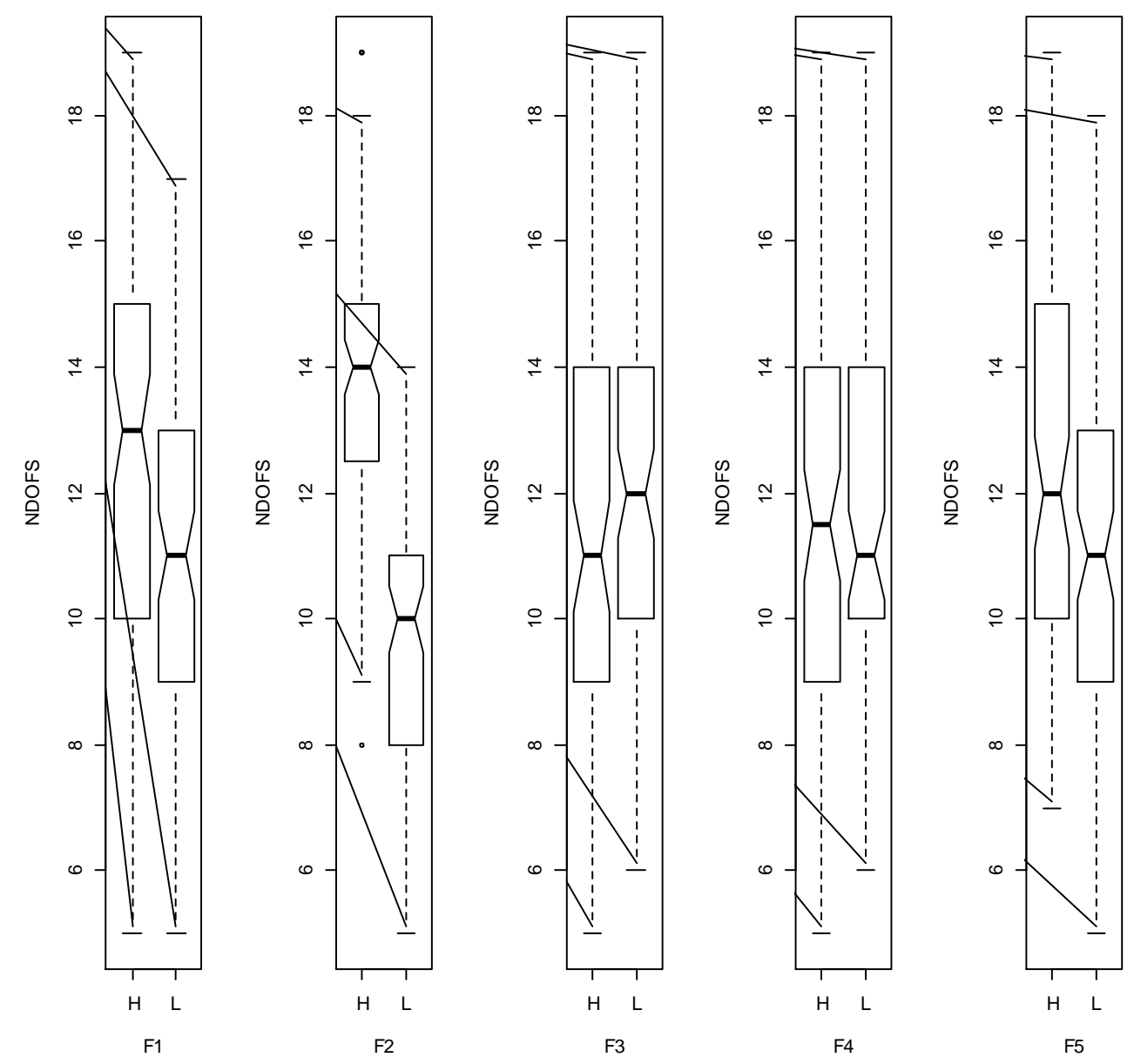

Figure 6. NDOFS boxplot for each factor 


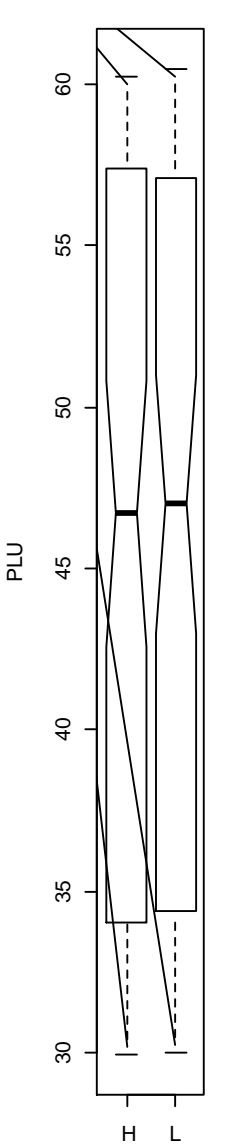

F1
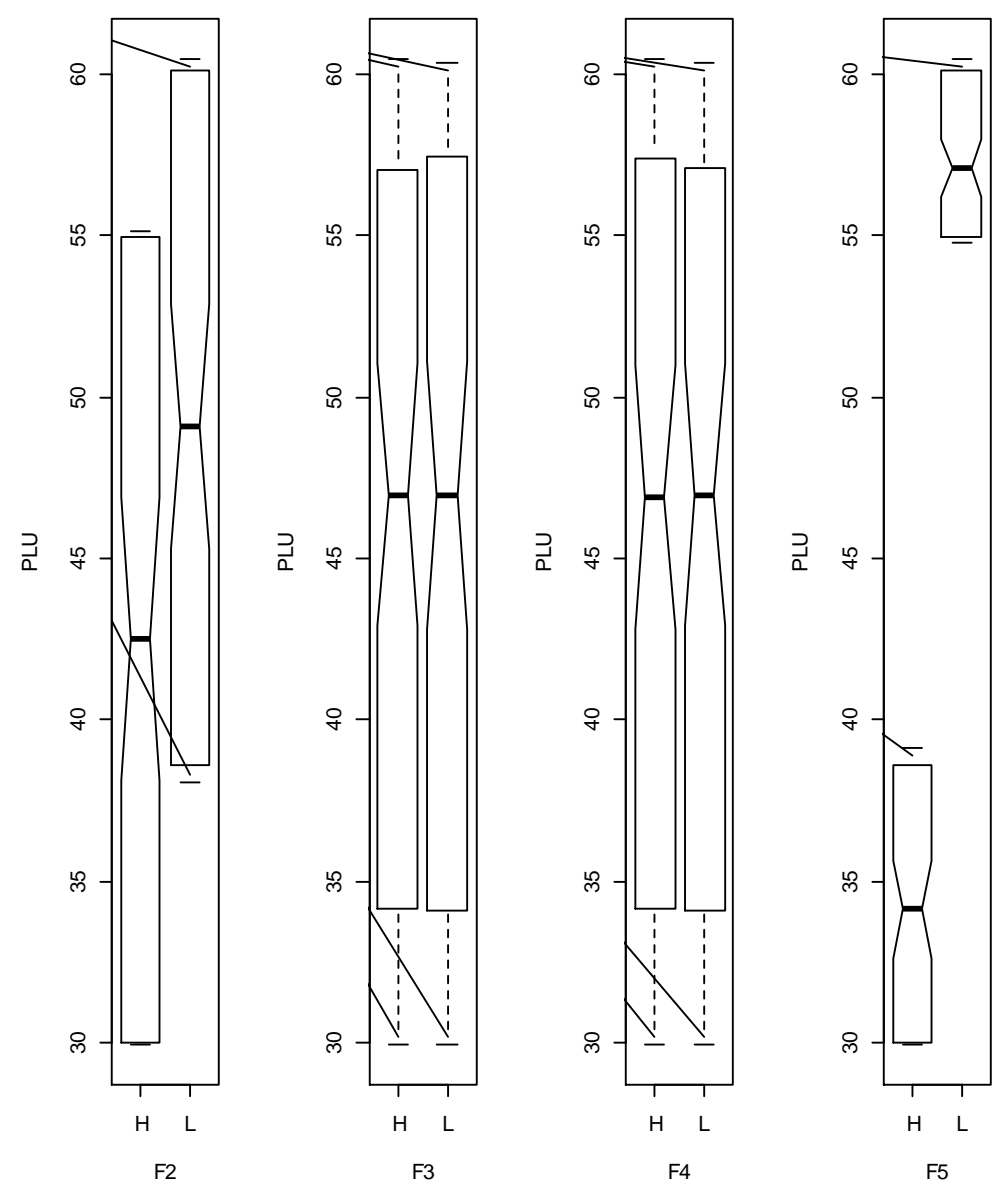

Figure 7. PLU boxplot for each factor 

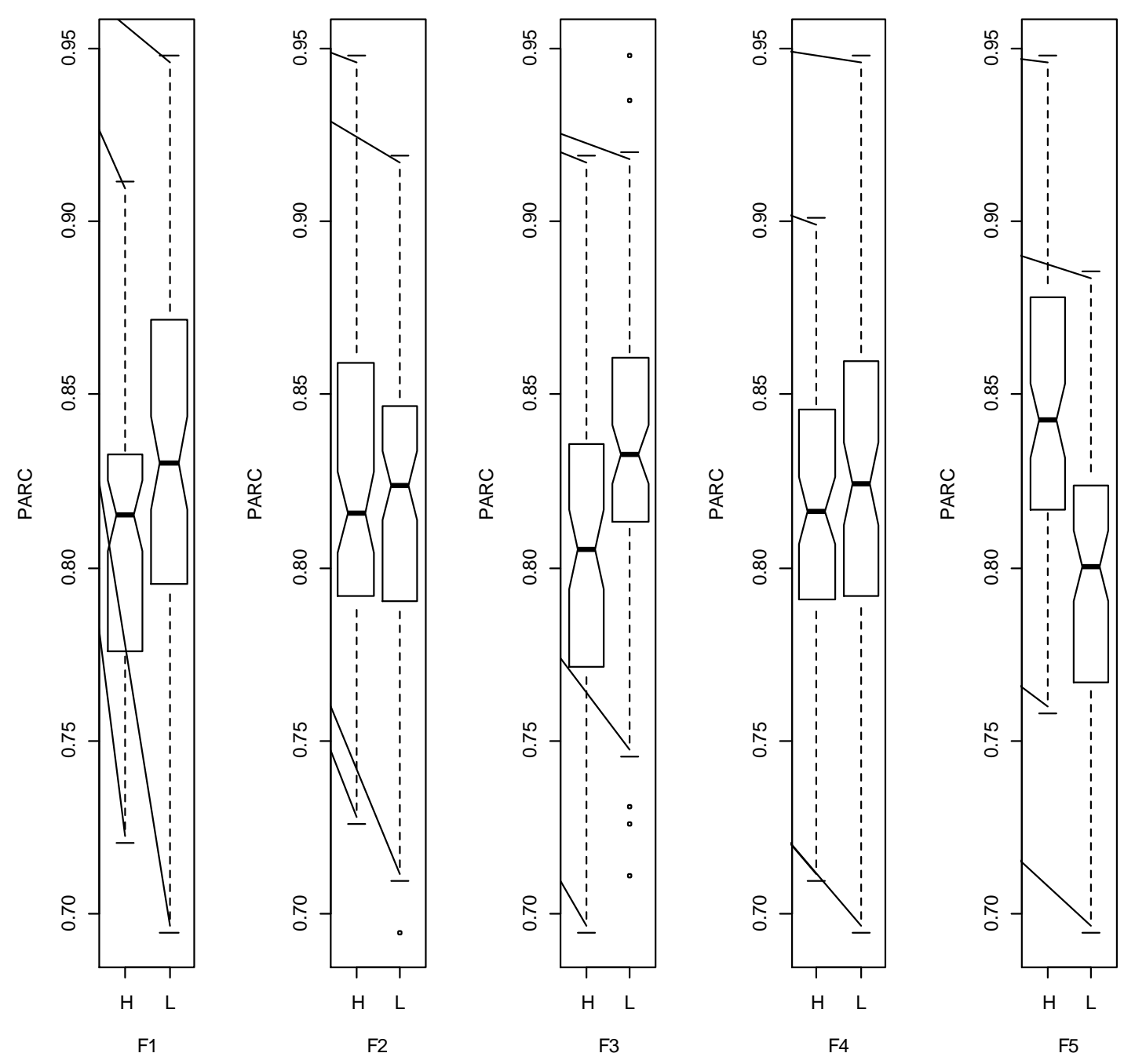

Figure 8. PARC boxplot for each factor 


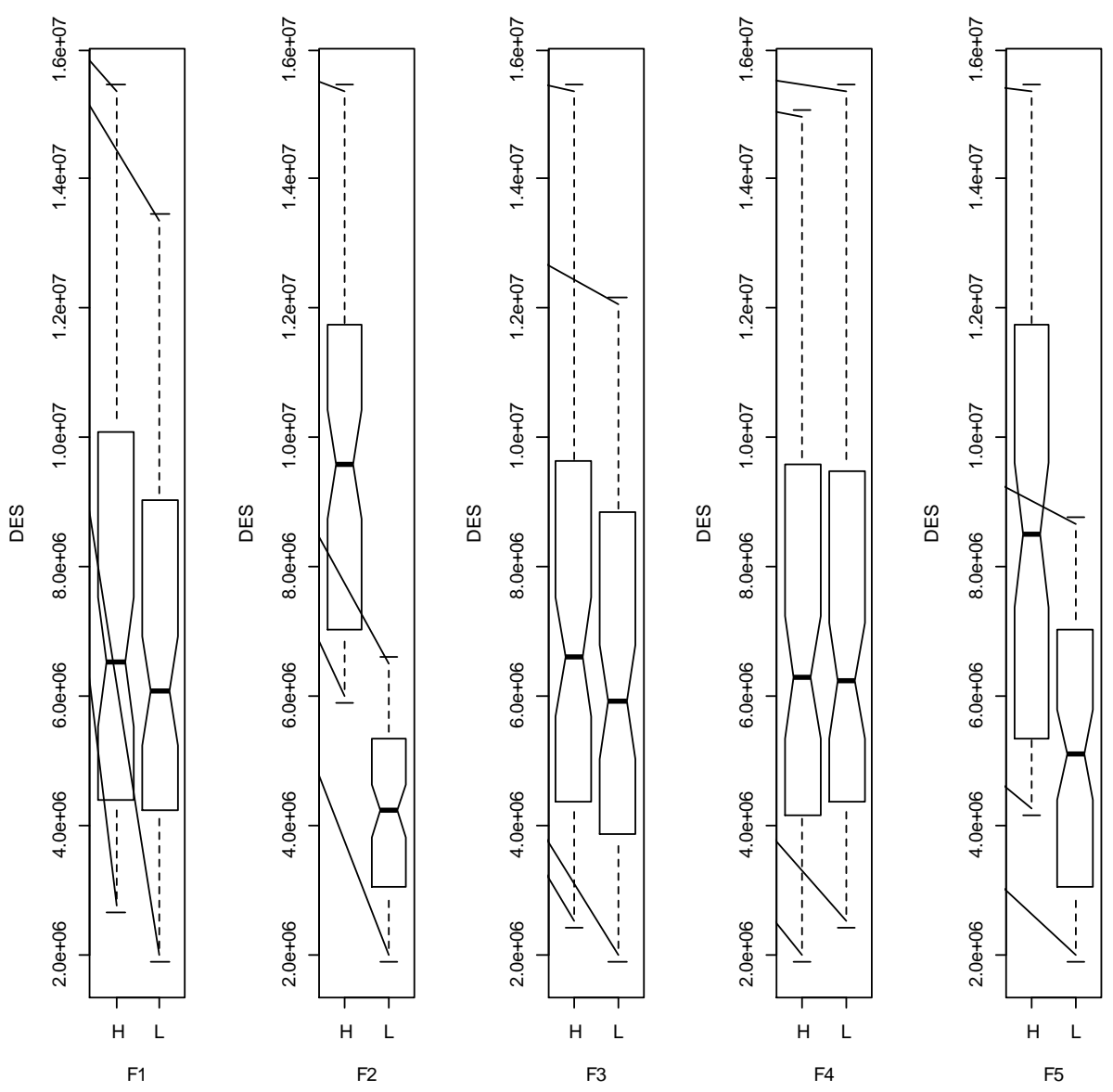

Figure 9. DES boxplot for each factor 

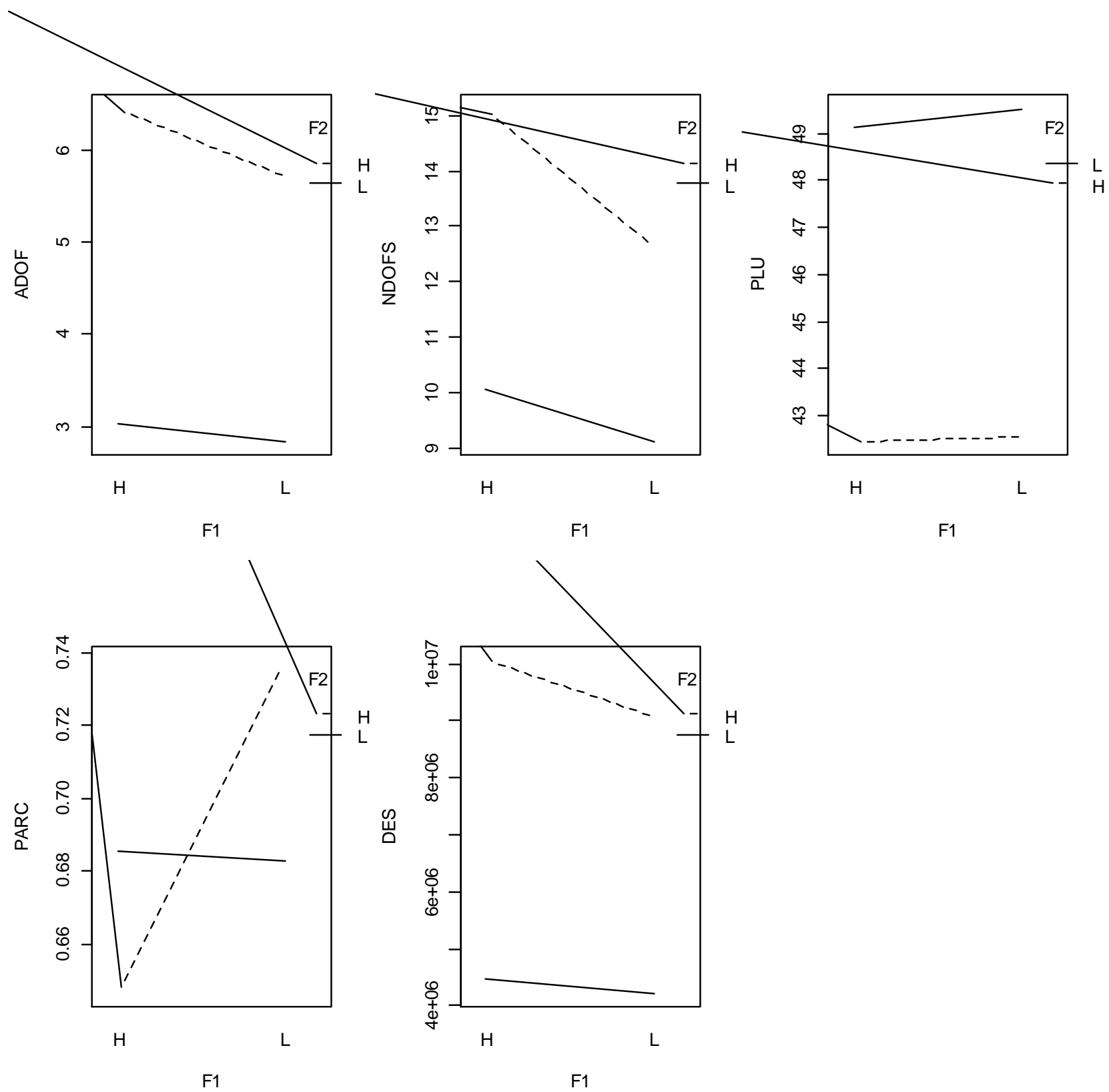

Figure 10. Interaction plots between F1 and F2 for the five metrics 


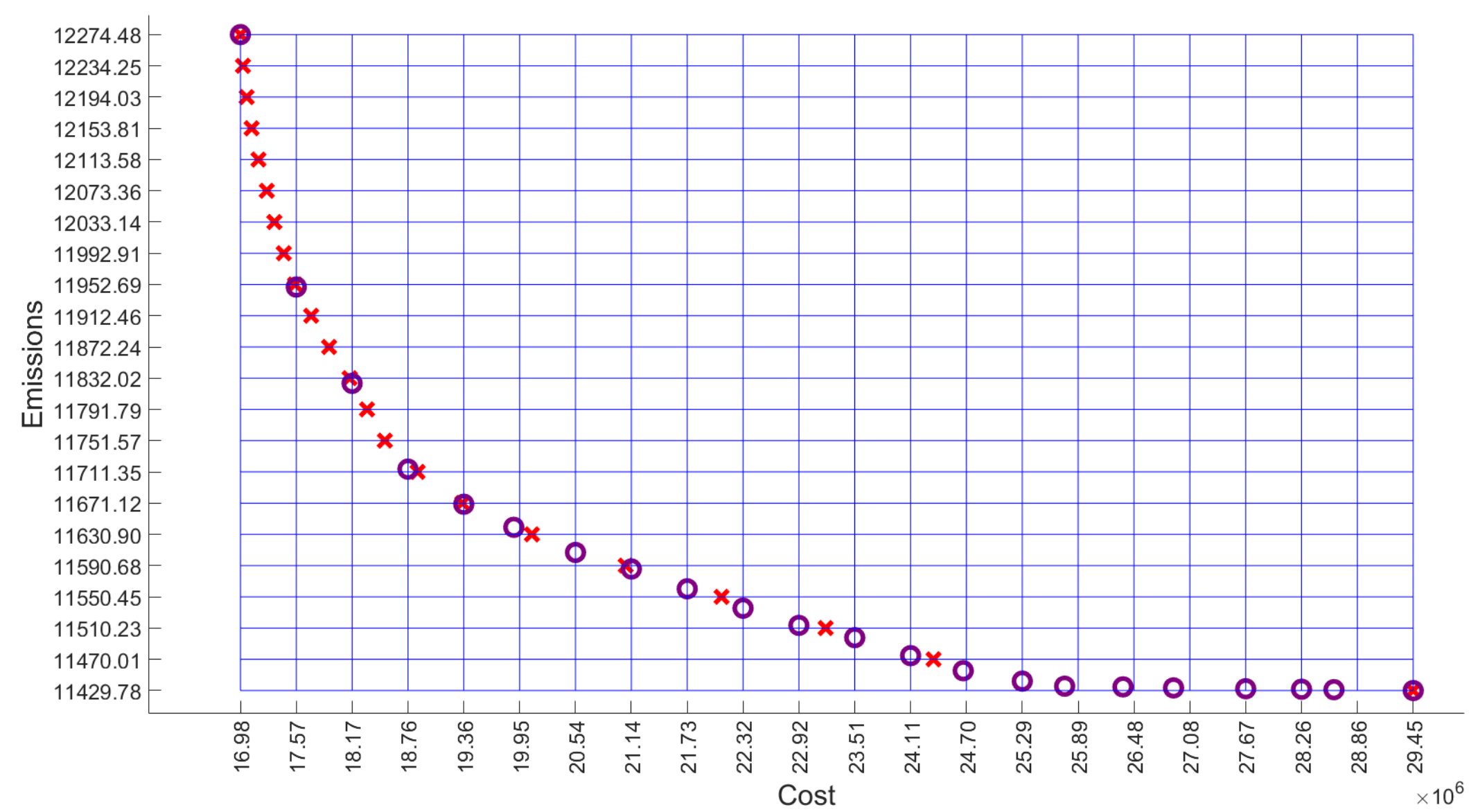

Figure 11. Comparison of PFs computed minimizing cost subject to bounds on emissions (cross) and minimizing emissions subject to bounds on cost (circle), for an instance corresponding to treatment $\langle\mathrm{L}-\mathrm{H}-\mathrm{H}-\mathrm{L}-\mathrm{H}\rangle$. Grid is defined by the bounds $\varepsilon_{i}$ affecting emissions and costs. 
Table 1. Values for the two levels corresponding to F2 (product complexity), depending on the value of $\mathrm{F} 1$.

\begin{tabular}{|r|c|c|c|c|c|c|c|c|}
\hline F1 & $\begin{array}{c}\text { Number } \\
\text { Suppliers, Plants, } \\
\text { Warehouses }\end{array}$ & $\begin{array}{c}\text { Number } \\
\text { Customers }\end{array}$ & F2 & Products & $\begin{array}{c}\text { Components/ } \\
\text { Product }\end{array}$ & Components & $\begin{array}{c}\text { Plants/ } \\
\text { Product }\end{array}$ & $\begin{array}{c}\text { Components/ } \\
\text { Supplier }\end{array}$ \\
\hline Low & 5 & 250 & Low & 4 & 2 & 8 & 3 & 3 \\
\hline Low & 5 & 250 & High & 7 & 4 & 8 & 5 & 5 \\
\hline High & 10 & 500 & Low & 4 & 2 & 8 & 3 & 3 \\
\hline High & 10 & 500 & High & 7 & 4 & 8 & 10 & 5 \\
\hline
\end{tabular}

Table 2. Levels corresponding to F3 (cost variability)

\begin{tabular}{|c|c|c|c|c|c|}
\hline \multirow{2}{*}{$\begin{array}{c}\text { Cost } \\
\text { Variability }\end{array}$} & \multicolumn{3}{|c|}{ Fixed costs } & \multicolumn{2}{|c|}{ Variable costs } \\
\hline & Suppliers & Plants & Warehouses & Mean & $\begin{array}{l}\text { Coef. } \\
\text { Variat. }\end{array}$ \\
\hline Low & $\mathrm{U}(580,000 ; 820,000)$ & $\mathrm{U}(1,000,000 ; 1,400,000)$ & $\mathrm{U}(290,000 ; 410,000)$ & $\mathrm{U}(5 ; 15)$ & 0.1 \\
\hline High & $\mathrm{U}(350,000 ; 1,050,000)$ & $\mathrm{U}(600,000 ; 1,800,000)$ & $\mathrm{U}(175,000 ; 525,000)$ & $\mathrm{U}(5 ; 15)$ & 0.3 \\
\hline
\end{tabular}


Table 3. ANOVA for ADOF

\begin{tabular}{|l|r|r|r|r|l|}
\hline $\begin{array}{l}\text { Analysis of Variance Table } \\
\text { Response: ADOF }\end{array}$ & \multicolumn{6}{|l|}{} \\
\hline & Df & Sum Sq & Mean Sq & F value & $\operatorname{Pr}(<\mathrm{F})$ \\
\cline { 2 - 7 } F1 & 1 & 8.76 & 8.76 & 10.074 & $0.001816^{* *}$ \\
\cline { 2 - 7 } F2 & 1 & 397.3 & 397.3 & 457.0132 & $<2.2 \mathrm{e}-16^{* * *}$ \\
\cline { 2 - 7 } F3 & 1 & 5.66 & 5.66 & 6.5135 & $0.011679^{*}$ \\
\cline { 2 - 7 } F4 & 1 & 0.14 & 0.14 & 0.1651 & 0.685061 \\
\cline { 2 - 7 } F5 & 1 & 182.18 & 182.18 & 209.567 & $<2.2 \mathrm{e}-16^{* * * *}$ \\
\cline { 2 - 7 } Residuals & 154 & 133.88 & 0.87 & & \\
\hline
\end{tabular}

Significance levels: $0 * * * \quad 0.001 * * \quad 0.01 * 0.05$.'

Table 4. Summary of the factors with clear influence in the different metrics, and their influence ( $\Downarrow$ means that as the factor goes from a low to high level, the corresponding metric decreases, while $\Uparrow$ means that the metric increases its value)

\begin{tabular}{|c|c|c|c|c|c|}
\cline { 2 - 6 } \multicolumn{1}{c|}{} & $\begin{array}{c}\text { F1 } \\
\text { Network size }\end{array}$ & $\begin{array}{c}\text { F2 } \\
\text { Product Compl. }\end{array}$ & $\begin{array}{c}\text { F3 } \\
\text { Cost variability }\end{array}$ & $\begin{array}{c}\text { F4 } \\
\text { Emissions } \\
\text { gen. }\end{array}$ & $\begin{array}{c}\text { F5 } \\
\text { Over- } \\
\text { capacity }\end{array}$ \\
\hline $\begin{array}{c}\text { ADOF } \\
\text { (Avg. difference } \\
\text { in open facilities) }\end{array}$ & $\Uparrow$ & $\Uparrow$ & & & $\Uparrow$ \\
\hline $\begin{array}{c}\text { NDOFS } \\
\text { (No. of different } \\
\text { open facilities) }\end{array}$ & $\Uparrow$ & $\Uparrow$ & & & $\Uparrow$ \\
\hline $\begin{array}{c}\text { PLU } \\
\text { (Percentage of } \\
\text { links used) }\end{array}$ & & $\Downarrow$ & & & $\Downarrow$ \\
\hline $\begin{array}{c}\text { PARC } \\
\text { (Percentage area } \\
\text { rectangle covered) }\end{array}$ & $\Downarrow$ & & & & $\Uparrow$ \\
\hline $\begin{array}{c}\text { DES } \\
\text { (Distance bet. } \\
\text { extreme PF points) }\end{array}$ & & $\Uparrow$ & & & $\Uparrow$ \\
\hline
\end{tabular}

